\title{
Efficacy of Indigenous Alcoholic Beverage, Areki, Against Ticks on Cattle in Woldia Area of Ethiopia
}

Melaku Wale ( $\triangle$ melakuwale20@gmail.com )

Bahir Dar University https://orcid.org/0000-0002-4189-8537

Eshetu Tadesse

Woldia Preparatory School

\section{Research Article}

Keywords: Cattle, Ectoparasites, Ticks, Organic pesticides, Risk factors, Ethiopia

Posted Date: October 20th, 2021

DOI: https://doi.org/10.21203/rs.3.rs-950237/v1

License: (c) (i) This work is licensed under a Creative Commons Attribution 4.0 International License. Read Full License 


\section{Abstract}

Ticks are a major group of ectoparasites of livestock. A study was conducted to determine the efficacy of locally brewed alcoholic beverage (areki) against ticks on cattle. A sample of 285 cattle owners were purposively selected from the study area. Experiment 1 was a spray of the test materials on affected body parts of animals (150 ml per animal). Treatments include untreated (negative control), areki, and commercial acaricide (positive control). Before spray, each animal was inspected for tick infestation, and the number, growth stage of the ticks was recorded including risk factors (age, sex, health status, feed status, size). Experiment 2 was a toxicity bioassay test of ticks, with four dilution levels with water, i.e., $100 \%, 50 \%, 25 \%$ and $0 \%$ areki by volume. In experiment 1 , areki and the commercial acaricide were equally effective. Significantly more live ticks were found on the control and more dead ticks on acaricide and areki. All dilutions were effective in the toxicity bioassay test. In contrast to dead ticks, live tick numbers after spray did not vary with respect to animal health status, body size, sex, breed type, feed supply, and residence (rural and urban). According to the regression analysis, some of the study sites, type of breeds, feed supply, health status of the animal, and spray treatments played significant role in the mortality of ticks (encouraging or discouraging mortality). In general, the current study showed that areki was a promising product for the management of ticks on cattle in Woldia area of Ethiopia.

\section{Introduction}

Ticks are obligate, blood feeding ecto-parasites that cause severe damage to the hides and skins of domestic cattle (belonging to the class Arachnida, Order Acari). Ticks reduce foreign exchange and transmit tick borne diseases (Wall and Shearer 2001). In Ethiopia, several species of ticks belonging to the genera Amblyomma, Boophilus, Rhipicephalus, Hyalomma and Haemaphysalis have been reported (Pegram et al. 1981; Walker et al. 2014). Over 79 different species are found in eastern Africa but many of these appear to be of little or no economic importance (Cumming 1999). Out of over 79 tick species in Ethiopia, 47 species of ticks infest livestock. Most of them are vectors as they transmit disease causing agents and also damage animal skins and hides (Kassa 2005). They reduce the quality of hides and skins, milk, wool, general productivity and increase the susceptibility to other diseases (De Castro 1997).

Economic and veterinary importance of ticks is high; their transmission of tick-borne diseases remains a challenge for the cattle industry in tropical and subtropical areas of the world and it is a priority for many countries in tropical and subtropical regions (Lodos et al. 2000). Estimates show that $80 \%$ of the world's cattle are infested with ticks (Minjauw and McLeod 2003) and the production of over 1 billion cattle and a similar number of sheep around the world is affected (Estrada-Peña 2001). The annual global cost associated with tick and tick-borne diseases in cattle ranges between 13.9 and 18.7 billion USD (De Castro 1997). Cattle are a prime resource and assets for the people and government of Ethiopia. The country has the largest cattle population in Africa, estimated at 35 million heads (CSA 2002). Ticks prefer to attack the axial, the scrotum and udder, the groin and the belly regions of the animal. Some species were found primarily on the back and neck and they prefer the part of the body under the tail and the 
vulva regions of the animals. Dipping or spraying animals with chemical acaricides is the conventional tick control method. Also, motorized or hand-sprayers can be used (Jongjan et al. 1987).

Ticks can be controlled with chemical acaricides, though, continual uses and misuses result in resistant tick populations and toxicity to animals and the environment (Furlong et al. 2004). Botanical pesticides, on the other hand, are not toxic, do not impact pollinators and natural enemies and they are locally available and cheap. Ethanol and methanol can be used as alternatives to acaricides (Fernandez et al. 2012). Therefore, the present study was undertaken to determine the efficacy of the Ethiopian local alcohol (areki) against ticks on cattle in 2017 to 2018.

\section{Materials And Methods}

\section{Description of study area}

The study was carried out in Woldia area, located $360 \mathrm{~km}$ east from Bahir Dar (the regional capital) and $520 \mathrm{~km}$ north east of Addis Ababa, Ethiopia, in 2017/2018. The study area has an average elevation of about $1900 \mathrm{~m}$; much of the year is warm during the day and cool during the night. According to Sirinka Agricultural Research meteorological data, the annual rainfall is between 550 and $600 \mathrm{~mm}$ with a minimum temperature of $15^{\circ} \mathrm{C}$ and a maximum of $31^{\circ} \mathrm{C}$ (2017-2018 data). Livelihoods around Woldia area comprise crop production and livestock rearing. The main rains are received during the summer season (June to August/September) and a small second rainy season in the spring (March to May). Major food crops grown include sorghum, teff, maize and chickpeas. Vegetables and fruits such as tomato, onion, pepper, papaya, banana, orange and coffee are grown.

Livestock production is an integral part of the farming community in the area. Cattle, sheep, goats and poultry provide food and income while donkeys are the means of transport of goods. Land preparation (tillage) is also conducted using oxen. According to Woldia Agriculture Office (Pers. Comm., 2010), the livestock population of Woldia area was about 22 thousand, out of which 14 thousand were cattle.

\section{Sampling procedure}

Twenty families each of the sub-urban and rural areas who rear cattle for beef or milk were randomly chosen for the study. Agreement was made that allowed the researcher to investigate the tick condition of their cattle. Heavily infested cattle were purposively chosen to test the product against the ticks. A total of 285 animals were chosen and the treatments applied.

\section{Experiment 1. Direct spray on animals}

Treatments include an indigenous alcohol brewed and known locally as areki, along with a commercial acaricide Amitraz 12.5\% and an untreated control (pure water spray), and applied at a rate of $150 \mathrm{ml}$ per animal (Figure 1). The ethanol content of traditionally distilled areki varies between a mean of $37 \%$ (range: $30-40 \% \mathrm{v} / \mathrm{v}$ ) of the ordinary type to $48 \%$ (range: $38-48 \% \mathrm{v} / \mathrm{v}$ ) of the more refined one (dagim areki) 
(Tadesse et al. 2017). We used the ordinary type for this study. Amitraz is an antiparasitic active ingredient that belongs to the chemical class of the amidines used in veterinary medicine in livestock and pets against some external parasites (lice, mites, ticks) and against agricultural pests. Water was used as negative control, and the commercial acaricide as positive control, which is currently applied at a rate of 1 $\mathrm{ml}$ per litter of water (manufacturer's recommendation).

\section{Data collection}

The condition of each animal or potential risk factors that are anticipated to contribute for the occurrence of ticks, i.e., sex, age, health status, feed supply and size of the animal, was recorded, then inspected for tick infestation at each study site. The number of ticks was recorded sorted into different growth stages (nymphal or adult stage). After that, the treatments were applied on the animals using household sanitary atomizers as aerosols. Spray volume was calibrated first by using water. The amount of liquid applied was $150 \mathrm{ml}$ per animal. Spray droplet size was kept as small as possible, which was manipulated by adjusting the spray nozzle. Number of dead and live ticks was counted after one week of spray.

\section{Experiment 2. Toxicity bioassay of areki on ticks}

Treatments for this bioassay were rates of dilution with water of areki, i.e., all areki ( $100 \%$ areki, as positive control), half areki ( $50 \%$ areki and $50 \%$ water), quarter areki (25\% areki and $75 \%$ water) and no areki ( $100 \%$ water, as negative control) by volume. Including the untreated check (water), there were four treatments, replicated five times. Adult ticks were removed from animals by using forceps and used immediately for the test. Twenty ticks were used under each treatment. Each tick was kept in vials containing $5 \mathrm{ml}$ of the particular treatment (in vitro adult immersion test) for 2 minutes (Figure 2). After that, the ticks were removed and closely observed under a dissecting microscope for any sign of death. Observations were made on ticks (whether dead or alive) and data recorded twice, i.e., soon after treatment application and after $24 \mathrm{~h}$. The data recorded twice were then summed up with respect to treatments ready for analysis. The viability of the ticks was checked by probing with a needle, and ticks were considered dead if no reaction was observed.

\section{Data analysis}

Analysis of variance (ANOVA) was conducted using the general linear model $(\mathrm{glm})$ procedure of the statistical analysis software (SAS) (2016) to determine the differences in mortality among treatments. Regression analysis was invoked to determine if there were any relationships between number of ticks and animal characteristics (risk factors) such as sex, size, breed type, feed supply, health status and site. Sex (male, female), size (small, large), breed type (local, improved), feed supply (adequate, inadequate), health status (good, bad), site (various sites where the study was conducted). These variables and their levels were determined by the researchers on the basis of educated guess and common sense.

\section{Results}




\section{Experiment 1. Direct spray on animals}

Number of ticks before spray was supposed to be the same across treatments but some variation was observed on nymphs (but not on adults). One week after spray, on the other hand, areki and the commercial acaricide had comparable number of ticks alive. Significantly more ticks were found alive on the control than on areki and the commercial acaricide treatments (Table 1). Number of dead ticks was significantly higher on the acaricide and on the areki than the control (Table 1). No ticks were found dead on untreated animals. Percent reduction in tick population followed similar pattern.

Table 1. Efficacy of areki and acaricides against ticks on cattle.

\begin{tabular}{|c|c|c|c|c|c|}
\hline \multirow[b]{2}{*}{ Treatments } & \multicolumn{2}{|c|}{ Before spray } & \multicolumn{2}{|c|}{ After spray* } & \multirow[b]{2}{*}{ Reduction (\%) } \\
\hline & Nymphs & Adults & Alive & Dead & \\
\hline Commercial acaricide & $18.62 a$ & $3.82 a$ & $1.17 b$ & $21.26 a$ & $95.99 a$ \\
\hline Areki & $14.61 b$ & $3.84 a$ & $1.44 \mathrm{~b}$ & $17.01 \mathrm{~b}$ & $93.62 b$ \\
\hline Control & $19.76 a$ & $4.33 a$ & $24.10 \mathrm{a}$ & $0.00 c$ & $0.00 c$ \\
\hline
\end{tabular}

Means within a column followed by the same latter(s) are not significantly different according to Tukey HSD at $\mathrm{a}=0.05 ;$ *nymphs and adults.

\section{Experiment 2. Toxicity bioassay of (areki) on ticks}

Between 18 and 20 adult ticks were exposed to areki diluted in water in four levels, all areki (100\%), half areki ( $50 \%$ areki and $50 \%$ water), quarter areki ( $75 \%$ water and $25 \%$ areki), and no areki (all water). All ticks exposed to all areki died; $95 \%$ of those treated with quarter areki and a mere $5 \%$ of those with pure water died. According to this test, water containing a quarter of its volume of areki could kill most ticks (Figure 3).

Figure 3. Knock down effect of local areki on ticks of cattle (toxicity bioassay test).

\section{Risk factors}

\section{Health status}

The health status of cattle was qualitatively categorized in to good or bad. According to the results of the analysis of variance, the health status of animals had significant effect on number of nymphs counted $(F=9.49, P=0.0023)$, on adults $(F=40.86, P<0.0001)$, on total number of ticks $(F=21.45, P<0.0001)$, number of dead ticks $(F=21.37, P<0.0001)$, percent tick mortality $(F=5.17, P<0.0237)$, but not in number of ticks alive $(F=0.25, P=0.6156)$. Healthy looking animals had less tick load (Table 2$)$. Tick mortality was slightly higher on animals that looked sickly (Table 2).

\section{Animal body size}


The body size of cattle was qualitatively categorized into big or small. Size of animals did not matter; number of nymphs $(F=0.08, P=0.7779)$, adults $(F=0.67, P=0.4149)$, total number of ticks $(F=0.26$, $P=0.6099)$, number of ticks alive $(F=1.33, P=0.2423)$, number of dead ticks $(F=3.04, P=0.08)$, and in percent tick mortality $(F=3.35, P=0.0681)$ (Table 2$)$.

\section{Area of residence}

Generally, tick infestation of cattle did not vary between urban and rural areas. There was no significant difference in number of nymphs $(F=0.51, P=0.47)$, adults $(F=1.02, P=0.3135)$, total number of ticks $(F=0.03, P=0.8658)$, number of ticks alive $(F=0.05, P=0.8276)$, number of ticks dead $(F=0.15, P=0.69)$, percent tick mortality $(F=0.03, P=0.85)$ (Table 2$)$.

\section{Animal feed status}

Feeding status of cattle was qualitatively classified into inadequate or adequate. Feed supply had significant effect on the occurrence of ticks: with nymph ( $F=4.57, P=0.0333)$, adult $(F=36.40, P<0.0001)$, total number of ticks $(F=14.16, P=0.0002)$, number of ticks dead $(F=13.71, P=0.0003)$, percent tick mortality $(F=4.24, P=0.0403)$. In turn not in number of ticks alive $(F=0.14, P=0.7133)$ (Table 2). More dead ticks were found on animals that did not have adequate feed.

\section{Sexes of animals}

Tick infestation did not vary between sexes of animals after spray. Also, sexes did not vary in the number of ticks alive $(F=3.75, P=0.0538)$, number of dead ticks $(F=0.32, P=0.5734)$ and percent tick reduction $(F=0.29, P=0.5927$ ) (Table 2). Before spray, a greater number of nymphal and adult ticks was found on male cattle. After spray, slightly more ticks were found alive on male cattle than the females. Numbers of dead ticks did not significantly vary.

\section{Animal breed type}

Improved and local breeds of cattle significantly varied in number of nymphs ( $F=10.82, P=0.0011)$, number of adult ticks $(F=3.98, P=0.0471)$, total number of ticks $(F=10.33, P=0.0015)$, number of dead ticks $(F=12.05, P=0.0006)$, but not in number of ticks alive $(F=0.34, P=0.5612)$ and percent reduction of ticks $(F=2.14, P=0.1443)$. Generally, the local cattle breed carried more tick load (Table 2$)$. 
Table 2. Effects of the health status, body size of cattle, area, level of feed supply, sexes, and breed type of animals on the infestation level of ticks.

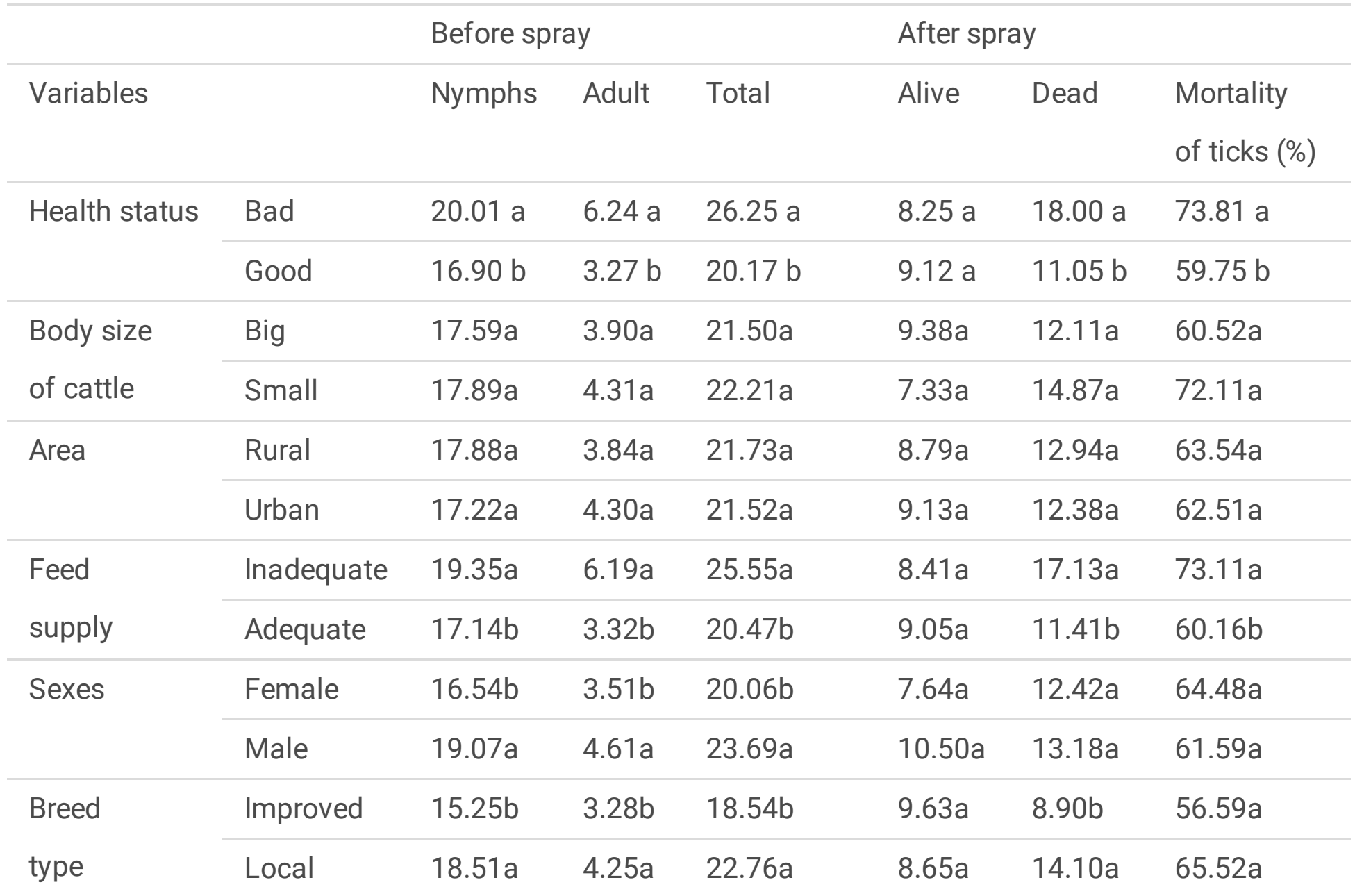

Means within a column followed by the same letter(s) are not significantly different according to Tukey HSD at $\mathrm{a}=0.05$

\section{Variation of infestation in different localities}

\section{Before spray}

Tick infestation of cattle varied among study sites before spray. There was significant difference among sites in member of nymphs $(F=2.91, P<0.0018)$ and in total number of ticks $(F=1.87, P<0.0490)$ but not in the number of adults $(F=0.67, P=0.7529)$, number of ticks alive $(F=0.57, P=0.83)$, number of dead ticks $(F=1.42, P=0.170)$, percent tick mortality $(F=3.35, P=0.0681)$. Number of nymphs was higher at Kibikalo and Adenguar; it was lower at Woldia kebeles 1 to 3 . Number of adults ranged between 22 at Woldia kebeles to 153 at Adengur (Figure 4).

\section{After spray}

Tick mortality was higher at Kibikalo followed by Adengur (Figure 4). Survival was less at Woldia kebeles. More alive ticks were found in Woldia Defergie. 
Figure 4. Effect of spraying local alcoholic beverage (areki) against ticks on cattle in different study sites in Woldia area, Ethiopia (2017/18).

\section{Regression analysis}

\section{Mortality}

A strong relationship was obtained between tick mortality and explanatory variables $\left(F_{18,266}=40.4\right.$, $P<0.0001, R^{2}=0.73$ ). Overall, sites, feed supply, health condition and the spray treatments played significant role in the regression model (Table 3 ).

Table 3. Relationship between tick mortality and independent variables.

\begin{tabular}{lllll}
\hline Term & Parameter estimates & Std Error & t value & P value \\
\hline Intercept & 12.6363 & 1.3993 & 9.03 & $<.0001$ \\
\hline Area[Rural] & 1.0144 & 0.6774 & 1.50 & 0.1355 \\
\hline Site[Adengur] & 0.8923 & 1.4277 & 0.63 & 0.5325 \\
\hline Site[Amayemicha] & 0.5123 & 1.3953 & 0.37 & 0.7138 \\
\hline Site[Gedo] & 2.2137 & 1.1891 & 1.86 & 0.0638 \\
\hline Site[Geneto] & -1.6559 & 1.3427 & -1.23 & 0.2186 \\
\hline Site[Gubo] & -0.6872 & 1.1210 & -0.61 & 0.5404 \\
\hline Site[Jarsa] & -1.2034 & 1.2114 & -0.99 & 0.3214 \\
\hline Site[Kibikalo] & 2.5472 & 1.1154 & 2.28 & 0.0232 \\
\hline Site[Mechare] & -2.5856 & 1.2865 & -2.01 & 0.0455 \\
\hline Site[Sirinka] & -3.3773 & 1.2187 & -2.77 & 0.0060 \\
\hline Site[Woldia] & 0 & 0 &. &. \\
\hline Age (years) & -0.0984 & 0.3065 & -0.32 & 0.7484 \\
\hline Sex[F] & -0.1857 & 0.4498 & -0.41 & 0.6801 \\
\hline Body size[big] & 0.4683 & 0.7953 & 0.59 & 0.5565 \\
\hline Breed[improved] & -1.4612 & 0.4541 & -3.22 & 0.0015 \\
\hline Feed supply[inadequate] & -3.9254 & 1.5139 & -2.59 & 0.0100 \\
\hline Health[poor] & 5.5519 & 1.4885 & 3.73 & 0.0002 \\
\hline Treatment[Commercial acaricide] & 8.1537 & 0.5132 & 15.89 & $<.0001$ \\
\hline Treatment[Control] & -12.1546 & -23.33 & $<.0001$ \\
\hline & & & & \\
\hline
\end{tabular}


The regression coefficient was positive for acaricide spray and negative for control, with spraying the alcohol (areki) as a baseline. It means that areki and the acaricide killed more and untreated ones killed less.

The coefficients for inadequate feed supply and improved breeds were both negative, meaning mortality was not enhanced under these conditions. In contrast, poor health status of the animal contributed positively to tick mortality. That means the poorer the health condition of the animal, the more likely ticks die. The coefficients for study sites of Mechare and Sirinka were negative and for Kibikalo positive, indicating the role of discouraging and encouraging tick mortality, respectively. The rest of the other nominal factors did not contribute significantly. As a rule, the regression analysis takes one level of each nominal factor as a baseline.

\section{Discussion}

The bioassay test showed that all rates of dilution, i.e., $100 \%, 75 \%$ and $25 \%$, effectively controlled ticks. The lowest rate of dilution ( $25 \%$ areki) is recommended for adoption in future because of the low cost incurred.

The comparative assessment of the effect of areki (an alcoholic extract of cereal grains in Ethiopia comparable to ethanol produced in a factory) and a commercial acaricide against nymphs and adult ticks on cattle showed that areki was effective as an ethno-veterinary acaricide. Similar results reported from other countries such as in Benin (Dougnon et al. 2014; Adehan et al. 2016; Anagew et al. 2017; Ravindran et al. 2017). Pesticides of plant origin work in various ways against ticks. For example, using leaves of two varieties of Tephrosia vogelii was reported to be effective against ticks (Ndava et al. 2018). Therefore, the use of areki as a low cost acaricide in the study area is encouraging, considering the high cost of commercially manufactured acaricides, their undesirable environmental impact and risks to non-target organisms.

Tick infestation was higher on animals of poor health compared with good ones. Poor health status of cattle means poor defensive immunity and more tick infestation. On the other hand, the size of animals did not matter in the infestation level of ticks. In contrast, in other studies, body condition of cattle significantly influenced tick load on cattle (Tadesse et al. 2012; Eyo et al. 2014). In these foreign reports, animals with poor body condition had more ticks than animals with good body condition. Infestation of ticks did not significantly vary between rural and urban areas. This may be because the rural area is found near to urban areas, which has the same animal husbandry, weather condition and vegetation. Differences were, however, reported in other studies (Abebe et al. 2010). Tick density per animal varied among the different study sites. This might have come from differences in management and environmental setting. The current study corroborates previous reports of variable tick load across localities (Tesgera et al. 2017). In this study, tick infestations were higher in cattle of inadequate feed supply than those without. Good feed supply may boost the immunity of the animals and therefore reduce level of tick infestation. 
Ticks attacked more male cattle than female cattle. This may happen because oxen are used as draught power in land preparation and in threshing grains while female cows are milked. Eyo et al. (2014) reported similar observations while others found more tick burden on female cattle (Birru et al.

2011; Tesgera et al. 2017). More tick burden was recorded on the local breed than the improved animals. This may be because crossbreds were managed better than the locals (in terms of nutrition and health). Improved breeds are meant for beef or milk and that makes them high value animals and demand more investment. Similarly, in previous studies, local breeds were found more infested than the improved ones (Surafel and Amsalu 2012; Eyo et al. 2014).

\section{Conclusion}

During the current study, an effort was made to determine the efficacy of local areki (indigenously brewed ethanol) on parasitic ticks on cattle in Woldia area of Ethiopia. The results confirmed that the locally brewed alcohol was as effective as the commercial acaricide against nymphs and adult ticks on cattle. Risk factors such as area (rural and urban), site (villages or communities), breed types, feed supply, size of the animals (big or small), sex and health status of the animals were factors that contributed for the infestation. As low as $25 \%$ dilution with water of areki was found effective, which makes the product cost-effective. Areki is brewed as beverage from barley, sorghum, maize and other grains and is marketed throughout Ethiopia. Its traditional production ensures easy access to the product, which cattle keepers can employ in Woldia or anywhere in Ethiopia, wherever ticks pose problems. Commercial acaricides, on the other hand, have drawbacks because ticks develop resistance against them, they pollute the environment (also poison human handlers), supply is unpredictable and cost is high, they damage the skin of the animals treated, reduce the quality of milk and increase the susceptibility of animals to other diseases. Using areki can help prevent the side effects of commercial acaricides. It is, therefore, advisable to use local areki against ticks on cattle as ticks are also unlikely to develop resistance against this product.

\section{Declarations}

\section{Acknowledgments}

We like to thank the data enumerators, cattle owners, and Woldia District Animal Health Office staff for their support during the study.

\section{Funding statement}

The research fund was obtained through a local scholarship fund by Bahir Dar University, Ethiopia. There was no grant number. The writing of this paper was the responsibility of the authors and the funder was not involved.

\section{Conflicts of interest/competing interests}


There is no conflict of interest, whatsoever.

Availability of data and materials (data transparency)

Data are available from the corresponding author upon request.

Code availability (software application or custom code)

Not applicable.

\section{Authors' contributions}

The senior author (MW) identified the existing gap in knowledge, conceived the research idea, formulated the design, participated in field and laboratory work, analyzed the data and helped interpret the findings and eventually wrote the paper. The second author (SY) wrote the proposal, conducted the field and lab work, collected data and wrote the draft results.

\section{Ethics approval}

Not applicable.

\section{Consent to participate}

Not applicable.

\section{Consent for publication}

All parties including authors agree on its publication in the current form.

\section{Competing interests}

Not applicable.

\section{References}

Abebe, R., Fantahun, T., Abera, M., Bekele, J., 2010. Survey of ticks (Acari: Ixodidae) infesting cattle in two districts of Somali Regional State, Ethiopia. Veterinary World, 3(12), 539-543.

Adehan, B.S., A. Biguezoton, A., Adakal, H., Dossa, F., Dougnon, J.T., Youssao, E., Sessou, P., Aboh, B.A., Youssao, I.K., Assogba, N., Mensah, A.G., Madder, M., S. Farougou, S., 2016. Acaricidal activity of ethanolic and volatile extracts of the leaves of selected plants used in veterinary pharmacopeia on the larvae of Rhipicephalus Microplus in Benin. Veterinary Sciences, 49(1), 1-11.

Anagew, B., Abebaw, M., Zemene, M., Workneh, D., 2017. An In Vitro acaricidal efficacy assessment of crude methanolic and ethanolic extracts and latex secretion of Cryptostegia grandiflora against Amblyomma and Ornithodorus. Tick Species Nature Sciences, 15(4), 92-104. 
Birru, B., Neguse, T., Nigusu, K., Ababa, H., Araya, S., 2011. Status of bovine tick infestation, in GubaKoricha district in west Hararghe zone, east - Ethiopia. Global Veterinary, 7(6), 527-531.

CSA (Central Statistics Authority), 2002. Ethiopian statistical abstract, Addis Ababa, Ethiopia.

Cumming, G.S., 1999. Host distributions do not limit the species ranges of most African ticks (Acari: Ixodida). Bulletin of Entomological Research, 89, 303-327.

De Castro, J., 1997. Sustainable ticks and tick-borne disease control in livestock improvement in developing countries. Veterinary Parasitology, 71, 69-76.

Dougnon, J.T., Farougou, S., Kpodékon, M.T., Hounmanou, G., Hounnnonkpè, D., 2014. Comparative study of the effect of Tephrosia vogelii 's leaves ethanolic extract and Alfapor (Alpha-cypermethrin) on Amblyomma variegatumin Borgoucattle. International Journal of Biosciences, 5, 1-7.

Estrada-Peña, A., 2001. Forecasting habitat suitability for ticks and prevention of tick-borne diseases. Veterinary Parasitology, 98(1-3), 111-132. doi: 10.1016/s0304-4017(01)00426-5

Eyo, E.J., Ekeh, N.F., Ivoke, N., Atama, I.C., Onah, E.I., Ezenwaji, E.N., Ikele, B.C., 2014. Survey of tick infestation of cattle at four selected grazing sites in the tropics. Global Veterinary, 12(4), 479-486.

Fernandez, A., Rodriguez, R., Alonso, M., 2012. First report of a Rhipicephalus microplus tick population multi-resistant to acaricides and ivermectin in the Mexican tropics. Veterinary Parasitology, 183, 338342.

Furlong, J., Martins, J., Prata, M., 2004. Controle estratégico do carrapato dos bovinos. A Hora, 23, 53-56.

Jongjan, F., Zivkovic, D., Pegram, R.G., Tatchell, R.J., Fison, T., Latif, A.A., Paine, G., 1987. Ticks of the Blue and White Nile ecosystems in the Sudan with particular reference to Rhipicephalus sanguineus group. Experimental and Applied Acarology, 3, 331-346.

Kassa, B., 2005. Standard veterinary laboratory diagnostic manual. Veterinary diagnostic laboratory, College of Veterinary Medicine at the University of Illinois at Urbana, Urbana, IL, USA

Lodos, J., Boue, O., de la Fuente, J., 2000. Model to simulate the effect of vaccination against Boophilus ticks on cattle. Veterinary Parasitology, 87(4), 315-326.

Minjauw, B., McLeod, A., 2003. Tick-borne diseases and poverty: the impact of ticks and tick-borne diseases on the livelihoods of small-scale and marginal livestock owners in India and eastern and southern Africa. Available at: https://www.cabdirect.org/cabdirect/abstract/20063155090

Ndava, J., Wilbert, T., Mapuwei, T.W., Madoma, C., 2018. A comparative assessment of the acaricidal activity of Tephrosia vogelii on Rhipicephalus appendiculatus and Amblyomma variegatum in Makoni 
district, Manicaland Province, Zimbabwe. Journal of Entomology and Zoological Studies, 6(1), 11451150 .

Pegram, R.G., Hoogstraal, H., Wassef, H., 1981. Ticks (Acari: Ixodidae) of Ethiopia: I. distribution, ecology and host relationship of species infesting livestock. Bulletin of Entomological Research, 71, 339-359.

Ravindran, R., Juliet, S., Ramankutty, S.A. et al., 2017. Effects of ethanolic extract of the leaves of Pongamia glabra and Gliricidia sepium against Rhipicephalus (Boophilus) annulatus. Advances Animal Veterinary Sciences, 5(1), 1-6. doi: 10.14737/journal.aavs/2017/5.1.1.6

SAS Institute Inc., 2016. SAS ${ }^{\circledR}$ 9.4 Language Reference: Concepts, Sixth Edition. Cary, NC: SAS Institute Inc

Surafel, A., Amsalu, Y., 2012. Prevalence of cattle tick infestation in and around Haramaya district, eastern Ethiopia. Veterinary Medicine and Animal Health, 4(6), 84-88.

Tadesse, F., Abadfaji, G., Girma, S., Kumsa, B., Jibat, T., 2012. Identification of tick species and their preferred site on cattle's body in and around Mizan Teferi, southwestern Ethiopia. Veterinary Medicine and Animal Health, 4(1),1-5.

Tadesse, S., Chandravanshi, B.S., Ele, E., Zewge, F., 2017. Ethanol, methanol, acid content and other quality parameters of Ethiopian traditional fermented, distilled, and factory produced alcoholic beverages. SINET: Ethiopian Journal of Science, 40(1), 16-35.

Tesgera, T., Regassa, F., Giro, B., Mohammed, A., 2017. Study on prevalence and identification of ixodid ticks in cattle in Gursum district, East Hararghe Zone of Oromia Regional State, Ethiopia. Journal of Parasitology and Vector Biology, 9(4), 27-33.

Walker, A.R., Bouattour, A., Camicas, J.L., Estrada-Peña, A., Horak, I., Latif, A.A., Pegram, R.G., Preston, P.M., 2014. Ticks of domestic animals in Africa: A guide to identification of species. Bioscience Reports, Edinburgh, $127 \mathrm{pp}$.

Wall, R., Shearer, D., 2001. Veterinary ectoparasites, biology, pathology and control. 2nd edit. Wiley Blackwell

\section{Figures}



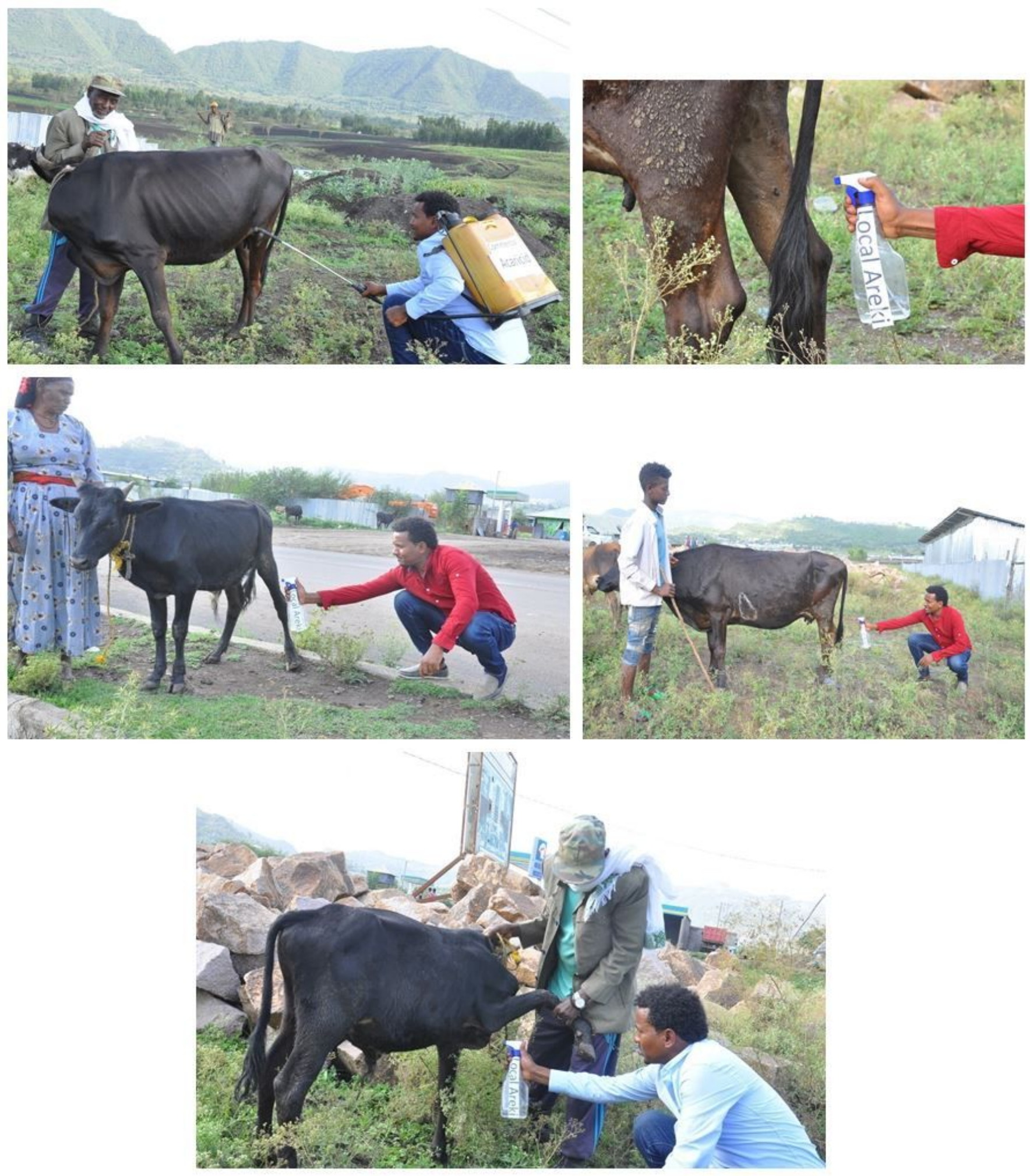

\section{Figure 1}

Direct spray of areki and commercial acaricide on cattle against ticks 

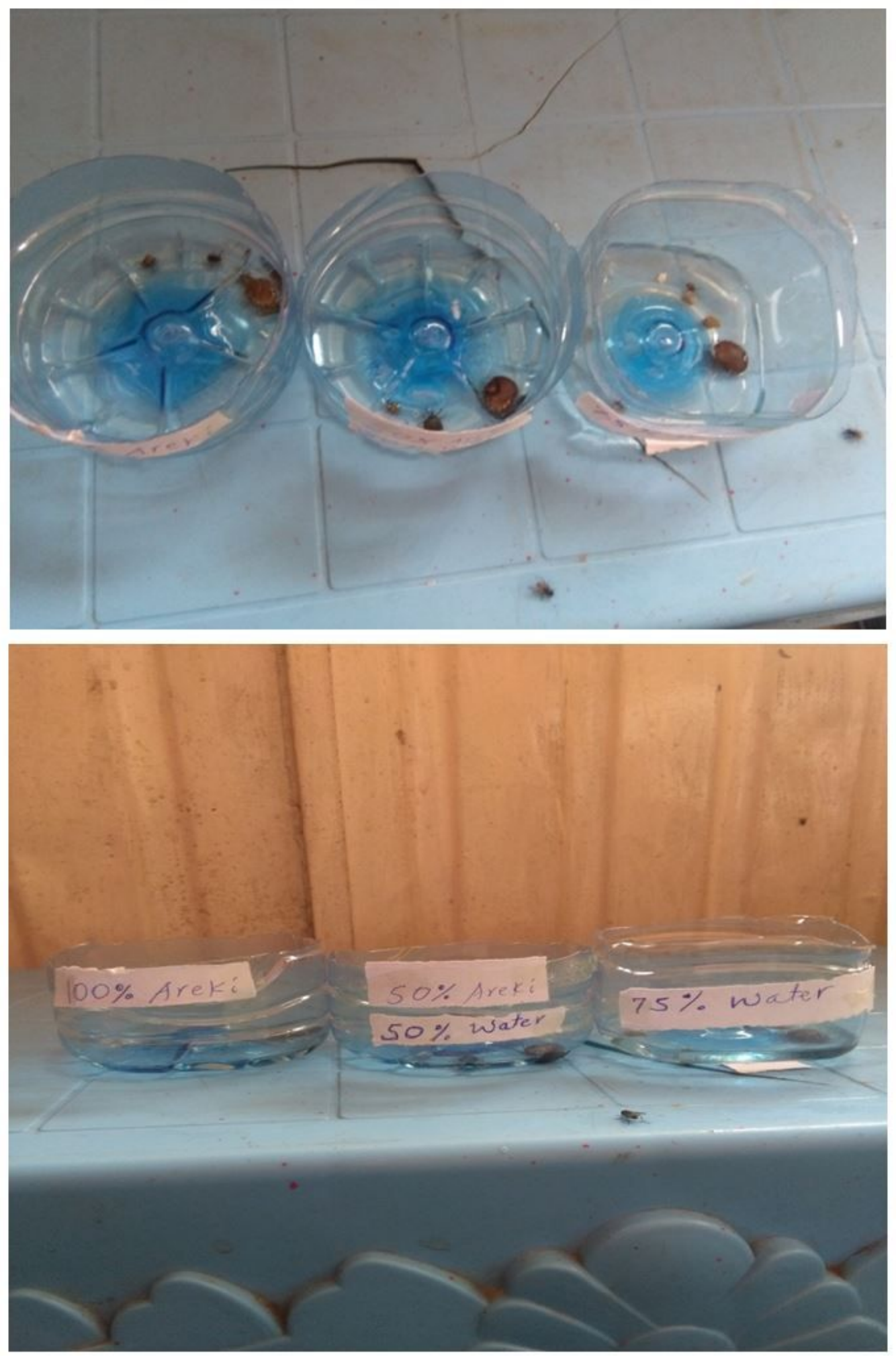

\section{Figure 2}

Toxicity bioassay test 


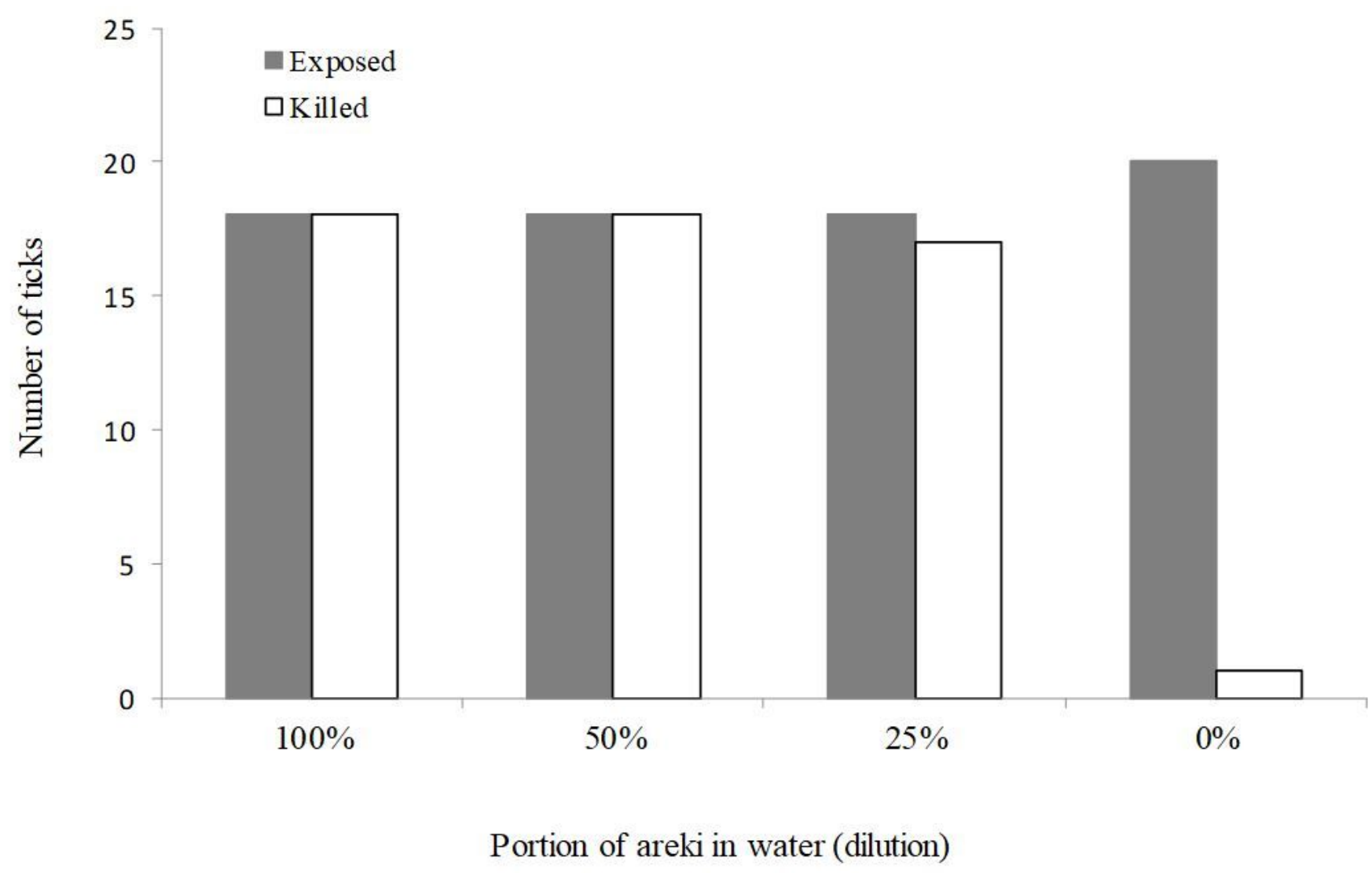

Figure 3

Knock down effect of local areki on ticks of cattle (toxicity bioassay test). 

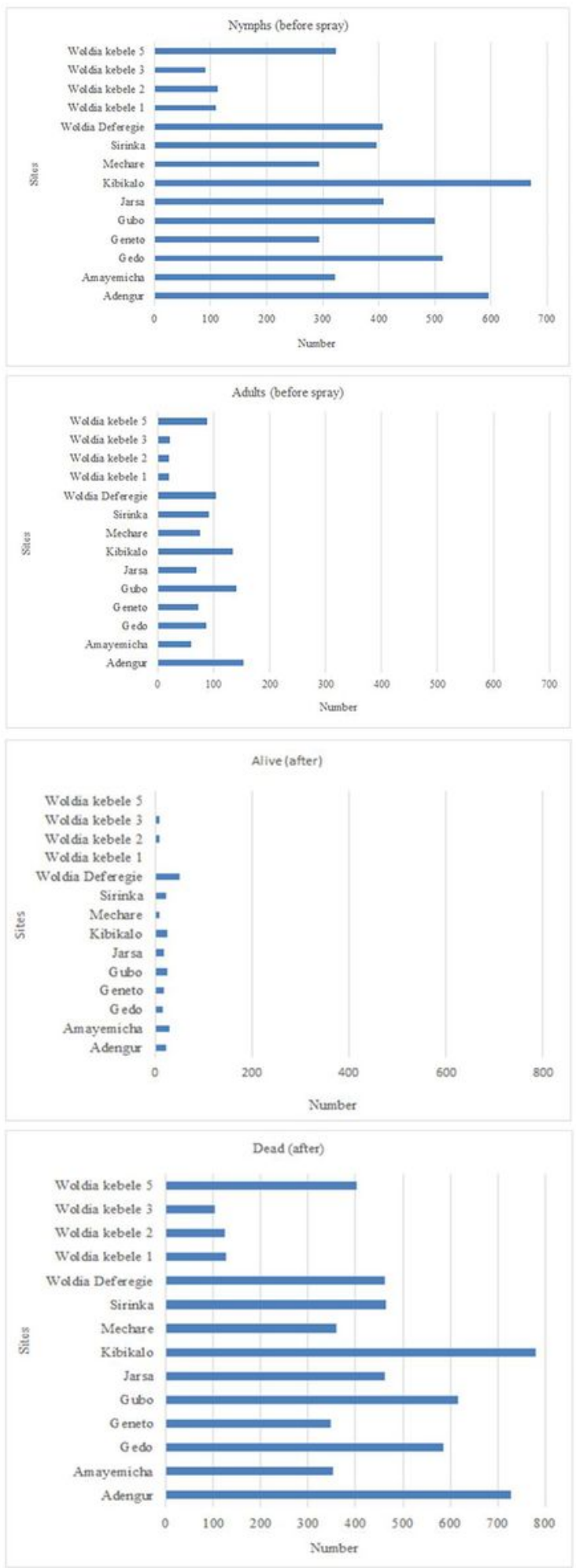

\section{Figure 4}

Effect of spraying local alcoholic beverage (areki) against ticks on cattle in different study sites in Woldia area, Ethiopia (2017/18). 